\title{
La planificación jurídica y sus funciones
}

\author{
Legal Planning and its Functions
}

Diego M. Papayannis*

Recepción y evaluación de propuesta: 24/10/2017

Aceptación: 26/02/2018

Recepción y aceptación final: 25/02/2019

Resumen: En este artículo se argumenta que la teoría de la planificación presentada por Scott Shapiro en su libro Legalidad ofrece una explicación mixta del fenómeno jurídico. Por una parte, pretende desentrañar la naturaleza del derecho, mediante un análisis conceptual que reconstruya fielmente el punto de vista interno. Por otra parte, Shapiro propone una explicación funcional del derecho que trasciende la perspectiva de los participantes. Ambas explicaciones iluminan aspectos diferentes de la práctica jurídica y, por ello, son complementarias.

Palabras clave: teoría de la planificación, legalidad, explicación interna, explicación funcional.

\begin{abstract}
In this article, it is argued that the planning theory advocated by Scott Shapiro in his book Legality presents a mixed explanation of the legal phenomenon. On the one hand, it aims to unravel the nature of law, through a conceptual analysis that faithfully portraits the internal point of view. On the other hand, Shapiro proposes a functional explanation of the law that transcends the perspective of their par-
\end{abstract}

* Profesor Serra Húnter de Filosofía del derecho e investigador de la Cátedra de Cultura Jurídica, Universitat de Girona, España. E-mail: diegomartin.papayannis@udg.edu. Con apoyo del proyecto "Seguridad jurídica y razonamiento judicial" (DER2017-82661-P), financiado por el Ministerio de Economía, Industria y Competitividad (España). 
ticipants. Both explanations illuminate different aspects of the legal practice and, therefore, are complementary.

Keywords: planning theory, legality, internal explanation, functional explanation.

\section{Introducción}

En su libro Legalidad, Scott Shapiro ofrece una teoría del derecho novedosa. Su propuesta más importante consiste en entender la actividad jurídica como una actividad de planificación social. Sin duda, esto supone un gran desafío, puesto que el concepto de plan o plan social, a diferencia de conceptos como norma, regla, principio, orden o mandato, ha sido tradicionalmente ajeno a la filosofía del derecho; naturalmente, el teórico tenderá a resistir la introducción de un nuevo concepto en el discurso explicativo a menos que ello resulte necesario. Creo que Shapiro tiene éxito en mostrar que el análisis del derecho en términos de planes sociales es una empresa plausible. A fin de cuentas, el lector de Legalidad descubre que en la presentación de Shapiro todas las piezas casan perfectamente. No obstante, como acabo de sugerir, mostrar que el derecho puede ser interpretado a la luz de la actividad de planificación es solo una parte de la tarea. Además, para convencer a los teóricos del derecho de que su proyecto merece el esfuerzo de aprender acerca de planes, su lógica, su racionalidad y estructura, Shapiro debe mostrar que incorporar este nuevo instrumental es un paso necesario para la plena comprensión de nuestras prácticas jurídicas. ¿Es posible prescindir de la idea de plan social o planificación? A diferencia de Shapiro, creo que sí es posible. Como intentaré mostrar, la teoría de Hart, que es tomada en Legalidad como el punto de referencia a superar, es en última instancia inmune a las críticas formuladas por Shapiro. Por lo tanto, una de las justificaciones que él ofrece para avanzar con su propia teoría carece de fundamento.

Pese a todo, creo que la teoría del derecho como plan es una teoría potente, en tanto admite dos lecturas diferentes. Conforme con la primera y más obvia, se trata de una explicación que toma en cuenta 
el punto de vista interno. En la línea habitual, Shapiro ofrece una comprensión de las prácticas jurídicas que aprueba lo que él denomina el test de la inteligibilidad ${ }^{1}$. Su explicación es transparente para los participantes. Por otra parte, también se puede considerar que Shapiro ofrece una explicación externa, en particular, una explicación funcional. Como intentaré mostrar, estos dos enfoques son muy diferentes, pero no incompatibles. De hecho, la información que se obtiene con un enfoque no está implicada por la que se obtiene con el otro y, por ello, son complementarios. Creo que una de las características más atractivas de la teoría de Shapiro es que ilumina algunos aspectos de los sistemas jurídicos que han sido frecuentemente ignorados por los teóricos del derecho; y han sido ignorados porque no se relacionan con una explicación del punto de vista interno. En este sentido, la teoría del derecho como plan destaca frente a sus competidoras. En mi opinión, su mérito no es haber superado el enfoque hartiano, dominante en la teoría del derecho anglosajona, sino que su valor radica en el alto grado de desarrollo de la teoría mixta que propone.

Comenzaré mi argumento explicando cómo se inserta la teoría de Shapiro en la tradición positivista y evaluando en qué medida, si acaso, supone un avance respecto de la propuesta de Hart. Luego, mostraré que la teoría de Shapiro puede ser entendida como una explicación funcional del derecho y, finalmente, defenderé que las teorías mixtas ofrecen una comprensión más profunda del fenómeno jurídico.

\section{La metodología jurídica hartiana y sus orígenes}

En los últimos 60 años la teoría del derecho se ha orientado a estudiar el fenómeno jurídico tomando en consideración la perspectiva de los participantes. Desde la publicación de The Concept of Law se ha popularizado la idea de que una explicación que no presenta una imagen del derecho reconocible por aquellos que aceptan las normas del sistema

1 Shapiro, S., "What is the internal point of view", Fordham Law Review, 75 (3), 2006, pp. 1157-1170, en pp. 1165-1166. 
como estándares legítimos de conducta es profundamente insatisfactoria. Para ofrecer una imagen reconocible o transparente, la teoría debe reflejar la manera en que los participantes razonan cuando identifican el derecho, lo aplican o, en general, lo utilizan como guía de conducta. Además, la explicación debe integrar coherentemente los rasgos más prominentes y familiares de la práctica en un relato expresado en términos más fundamentales que revele su sentido y/o sus relaciones y diferencias con otras prácticas sociales. Las críticas de Hart a Austin consistían en gran medida en poner de relieve la incapacidad de un modelo imperativista para dar cuenta de un conjunto de características que, en principio, no podrían dejar de incluirse en una descripción adecuada del fenómeno que se pretende explicar².

La necesidad epistémica de prestar atención al punto de vista interno viene como reacción al monismo metodológico que imponía para el estudio de las ciencias sociales el mismo canon de las ciencias naturales exactas ${ }^{3}$. Este movimiento enfatiza una verdad obvia: que las personas pueden ser comprendidas de un modo en que los fenómenos naturales no pueden serlo ${ }^{4}$. Lo relevante, para este modelo, no se encuentra en la observación de regularidades fácticas sino en su interpretación. La vida social tiene un significado para los individuos que la comparten y, por ello, la interpretación o la comprensión de estos significados, por medio del análisis del entramado conceptual de los participantes, pasa a ser un aspecto fundamental de las ciencias sociales. Este modelo se consolidó definitivamente con la sociología comprensiva de Max Weber ${ }^{5}$. En este sentido, hablaré por brevedad de

2 Pueden consultarse las críticas en Hart, H. L. A. (1961), The Concept of Law, Second Edition, Oxford, Oxford University Press, 1994 (en especial los capítulos II, III y IV) [N. E.: citado en la traducción de la primera edición de Genaro Carrió: Hart, H. L. A., El concepto de derecho, Buenos Aires, Abeledo-Perrot, 1963. En paréntesis se indican las páginas correspondientes a la traducción].

3 Véase Von Wright, G. H., Explanation and Understanding, London, Routledge \& Kegan Paul, 1971, pp. 3-4.

4 Sobre los orígenes de esta corriente, véase Macdonald, G. y Pettit, P., Semantics and Social Science, London-Boston-Henley, Routledge and Kegal Paul, 1981, p. 55.

5 Según Weber, "'explicar' es captar el complejo de significados en los que encaja una acción directamente inteligible en virtud de su significado intencional subjetivo". 
explicaciones internas y explicaciones externas, asumiendo que para las primeras (y no para las segundas) la fidelidad al punto de vista del participante es uno de los criterios de adecuación de la teoría ${ }^{6}$.

Acercando esta tradición metodológica a la filosofía jurídica, Hart se interesa por ofrecer una teoría interna, capaz de explicar el fenómeno de modo inteligible para los propios participantes ${ }^{7}$. Por ello, toma como punto de partida ciertas verdades obvias acerca del derecho, las que un hombre educado identificaría como centrales en todo sistema jurídico ${ }^{8}$. La teoría, sin embargo, debe de algún modo trascender este conocimiento común; debe aportar algo distinto de lo que todos los participantes ya saben. ¿Cómo puede brindarse una explica-

Véase Weber, M., Wirtschaft und Gesellschaft, Tubinga, J. C. B. Mohr, 1922. Citado por la traducción española de Giner, S., La acción social: Ensayos metodológicos, Barcelona, Ediciones Península, 1984, p. 18.

6 Las explicaciones internas a las que me refiero no adoptan el punto de vista interno, sino que solo lo describen. Ciertamente, algunos teóricos han extremado la metodología interna sosteniendo que el fenómeno no es plenamente comprensible para un observador externo. La plena comprensión del derecho no exige meramente tomar en consideración el punto de vista de los participantes, sino adoptarlo. Ello disolvería la dicotomía teórico-participante. Así, los enunciados del teórico serían de la misma índole que la de los participantes; serían enunciados internos, comprometidos, enunciados puramente normativos. Véase Dworkin, R., Law's Empire, Cambridge-Mass., Harvard University Press, 1986, pp. 62-65. A los efectos de este trabajo no analizaré este tipo de cuestiones, y solo asumiré que el proyecto hartiano tiene éxito en su pretensión de ser valorativamente neutral.

7 En realidad, Hart sigue la filosofia de Peter Winch (Winch, P., The idea of a Social Science and its Relation to Philosophy, Londres, Routledge \& Kegan Paul, 1958), y se ha señalado que existe una gran diferencia entre el enfoque de Winch y la sociología comprensiva de Weber. Según Winch, Weber se equivocaba al asumir que para ofrecer una interpretación en términos significativos el teórico debe apoyar sus conclusiones con evidencia estadística. Esta funciona en el esquema de Weber como un criterio objetivo para la validación de una entre varias interpretaciones posibles de los hechos sociales. En cambio, Winch consideraba que la estadística no era decisiva; la mejor interpretación es lo único que cuenta. Sin embargo, dejando de lado la referencia de Weber a la evidencia estadística, es posible conciliar sus posiciones, dado que el proyecto de Winch está comprometido con interpretaciones mejores que otras en términos de reglas sociales, lo cual seguramente no excluye la validación de interpretaciones plausibles mediante algún procedimiento objetivo. Véase Martin, M., Verstehen: The Uses of Understanding in the Social Sciences, New Jersey, Transaction Publishers, 2000, pp. 95-97.

8 Hart, op. cit., p. 3 (3-4). 
ción reconocible por los participantes pero que a la vez ilumine aspectos del derecho que escapan a sus propias interpretaciones? Es decir, ¿cómo puede el teórico ofrecer algo que la práctica no contiene expresamente y seguir al mismo tiempo comprometido con una metodología interna? El modo en que Hart realiza esta tarea es ofreciendo un análisis conceptual dirigido a esclarecer el marco general que organiza el pensamiento jurídico 9 . En parte, se trata de hacer explícito aquello que ya está implícito en la práctica. El objeto inmediato del análisis es el concepto de derecho, o nuestro concepto de derecho. ¿Qué valor tiene este tipo de estudios? Hart creía que el esclarecimiento de los conceptos mejoraba nuestra percepción del fenómeno. La idea es que, identificando los conceptos centrales de una práctica, determinando sus contenidos y relaciones mutuas profundizamos nuestra comprensión del fenómeno jurídico. Si el análisis se realiza correctamente, la explicación resultante debería ser reconocible por los participantes, tal vez previa reflexión, como el tipo de práctica que llevan adelante.

\section{La metodología de Shapiro y sus críticas a la teoría hartiana}

Como se verá, Shapiro comparte en gran medida la empresa hartiana, pero su presentación añade una carga metafísica que en la teoría de Hart es menos notoria. Según Shapiro, la pregunta más fundamental de la teoría jurídica es "iqué es el derecho?". Cuando se formula esta pregunta se desea conocer la naturaleza de su objeto de estudio. ¿Cómo se accede a esta naturaleza? De dos maneras. En ocasiones lo que nos interesa es dar una respuesta a la pregunta sobre la identidad: ¿qué hace que algo sea el tipo de cosa que es? ¿Qué hace que el derecho sea derecho y no una cosa distinta? Otras veces, nos interesa responder la pregunta de la implicación: ¿qué se sigue necesariamente de que algo sea lo que es? ¿Qué se sigue necesariamente de que algo 
sea derecho? Shapiro intenta responder ambas preguntas valiéndose del análisis conceptual ${ }^{10}$.

Para ello comienza enunciando una serie de verdades obvias acerca de cualquier práctica que consideraríamos jurídica ${ }^{11}$. Este listado sirve para evaluar las diferentes teorías de acuerdo con su capacidad para dar cuenta de lo que resulta más familiar del derecho. El proceso puede ser bastante complejo porque probablemente existan desacuerdos, en algunos casos muy profundos, respecto de cuáles son estas verdades obvias que toda teoría debe explicar. Cuando ello ocurre, nos quedamos sin criterios para evaluar las concepciones rivales. No obstante, debe tenerse en cuenta que las intuiciones de los participantes pueden fallar, por ello el propio listado de verdades obvias es provisional, lo que supone que está sujeto a revisión. Este proceso de evaluar las teorías por su adecuación a las verdades obvias y de revisar cuáles son verdades obvias a la luz de las teorías que se vayan proponiendo tiene lugar hasta que se llega a una suerte de equilibrio reflexivo, en el cual se logra una coherencia entre las piezas que conforman la explicación y las intuiciones iniciales. Una teoría que no pueda dar cuenta de todas las intuiciones centrales será insatisfactoria, pero no necesariamente equivocada. El análisis toma como punto de partida las intuiciones, pero no se agota en ellas. Así es como el análisis esclarece las fuentes de confusión. Las verdades obvias nos ayudan a construir las teorías,

${ }^{10}$ Véase Shapiro, S., Legalidad, Madrid-Barcelona, Marcial Pons, 2014, pp. 38-39.

${ }^{11}$ La lista preliminar de verdades evidentes acerca del derecho incluye, entre otras: a) todos los sistemas jurídicos tienen jueces que interpretan el derecho y cuya función es resolver conflictos; b) todos los sistemas jurídicos tienen instituciones para modificar el derecho; c) existen diferentes tipos de normas; algunas de ellas imponen deberes; d) las normas pueden ser aplicadas a quienes las crean; e) la autoridad jurídica siempre está conferida por normas jurídicas; f) las autoridades jurídicas pueden imponer obligaciones incluso cuando sus decisiones sean incorrectas; g) en todo sistema jurídico alguna persona o institución tiene autoridad suprema para crear derecho; h) saber qué requiere el derecho no es suficiente para estar motivado a obedecerlo; i) es posible obedecer el derecho incluso si se cree que no hay una obligación moral de hacerlo; j) los funcionarios pueden estar alienados; k) las preguntas jurídicas tienen respuestas correctas; 1) algunas veces, los tribunales interpretan el derecho de manera incorrecta; $\mathrm{m}$ ) algunos individuos conocen el derecho mejor que otros. Véase Ibidem, p. 41. 
y las teorías nos permiten revisar nuestros puntos de partida, lo que terminará corrigiendo nuestra percepción del fenómeno ${ }^{12}$.

Teniendo en mente estos rasgos comúnmente reconocidos, Shapiro presenta su concepción del derecho como plan social. Sin embargo, antes de hacerlo, debe justificar la necesidad de reemplazar el instrumental teórico tradicional por una idea tan novedosa como ajena a la filosofía jurídica. Por ello, analiza la capacidad de rendimiento de las teorías de Austin y de Hart a la luz de las características que en principio tienen los sistemas jurídicos. Le interesa fundamentalmente evaluar, por una parte, la coherencia lógica de estas teorías y, por la otra, la medida en que las representaciones que ofrecen de la práctica jurídica son fieles a la comprensión compartida de sus participantes ${ }^{13}$.

\section{III.1. La inteligibilidad y algo más...}

Según Shapiro, el modelo imperativo de Austin fracasa por las mismas razones que Hart detalla en The Concept of Law. No obstante, en algunas ocasiones, sus críticas son ligeramente distintas. Por ejemplo, mientras que la crítica de Hart se basa en que las normas de competencia no son órdenes respaldadas por amenazas, Shapiro agrega que el defecto de la teoría imperativa se muestra en que no logra reflejar las distintas funciones que cumplen dichas reglas. La función de las reglas de deber es limitar las libertades negativas, y la función de las reglas de competencia es incrementar las libertades positivas ${ }^{14}$. Adviértase que estas funciones no tienen por qué ser parte, ni derivarse necesariamente, de los conocimientos compartidos. Las funciones podrían tener un lugar central en el concepto de derecho, pero Shapiro no incluye en su listado de verdades evidentes ninguna característica a la luz de la cual pueda juzgarse si la incapacidad de dar cuenta de ellas es o no un defecto de la teoría. Por ello, esta crítica es en un sentido importante distinta de la hartiana.

12 Ibidem, p. 38 y ss.

13 Ibidem, p. 63.

$186 \quad{ }^{14}$ Ibidem, p. 95. 
Más adelante, las críticas de Shapiro retoman su cauce hartiano al señalar que el modelo imperativo no deja espacio para los buenos ciudadanos. Ellos no solo consideran que tienen razones morales para obrar según lo que dispone el derecho, sino que ven en el derecho una nueva razón moral para la acción. Para ellos, las sanciones no son un elemento motivacional, por lo tanto, no pueden ser el elemento definitorio de las normas que imponen deberes ${ }^{15}$.

Finalmente, Shapiro sostiene que una teoría como la de Austin hace incomprensible el modo en que estas personas piensan acerca de sus acciones:

[p]orque cualquier teoría que privilegia los hábitos y las sanciones por sobre las normas no solo ofrece una explicación pobre de las acciones de algunos ciudadanos sino que, todavía más importante, no explica la coherencia de sus pensamientos. No puede explicar el hecho de que piensan que el soberano tiene el derecho jurídico de gobernar, que el ejercicio de esa potestad genera obligaciones jurídicas, que sería jurídicamente incorrecto desobedecer, y que quienes son culpables de desobedecer el derecho deberían ser castigados por su infracción ${ }^{16}$.

En definitiva, la mayor objeción contra la teoría imperativa de Austin es que no reconstruye el punto de vista interno.

\section{III.2. Desconcertando a Hart}

Hart evidentemente no puede ser blanco de la misma crítica. Por ello, las discrepancias con esta teoría tienen un carácter más doméstico. Shapiro comparte en general el enfoque metodológico, pero encuentra insatisfactoria la teoría de Hart en dos puntos fundamentales: (1) su incapacidad de explicar cómo la autoridad jurídica es posible; y (2) su inconsistencia con la conocida ley de Hume, que impide derivar juicios

\footnotetext{
15 Ibidem, pp. 104-105.

16 Ibidem, p. 112.
} 
normativos a partir de juicios fácticos. Como se verá, ambos problemas están relacionados en cierta medida.

Desde el comienzo del libro Shapiro anuncia que parte de su análisis será planteado en forma de puzles o enigmas que desconciertan a los juristas. Estos son una buena estrategia porque nos muestran aspectos paradójicos de nuestras prácticas a los que debemos dar alguna respuesta si nuestro esquema conceptual ha de ser consistente. El más importante de estos puzles es la paradoja de la autoridad (the possibility puzzle). Explicado brevemente, la cuestión es cómo es posible el surgimiento de la autoridad jurídica si aceptamos dos proposiciones, por cierto muy razonables: (a) alguien tiene autoridad para crear nuevas normas jurídicas en la medida en que otra norma existente lo faculte a ello; y (b) una norma que faculta a un individuo a crear normas jurídicas solo existe si alguien con autoridad la ha creado ${ }^{17}$. Este planteo reedita el clásico problema del huevo y la gallina, y su objeto es desafiar la propia idea de autoridad.

Austin resuelve la paradoja de la autoridad rechazando la proposición (a). El soberano tiene autoridad porque puede coaccionar a los súbditos. La autoridad no proviene de las normas, sino que las normas provienen de la autoridad. El problema de este enfoque es que resulta perfectamente plausible (y habitual) que una autoridad sea reconocida como tal antes de promulgar ninguna norma.

Hart asume una estrategia distinta, que consiste en rechazar la proposición (b). Mientras que la autoridad requiere haber sido conferida por normas, las normas pueden ser creadas por quienes carecen de autoridad. La idea es que los grupos pueden crear reglas sociales mediante sus prácticas. Para Hart, en todo sistema jurídico existe una regla de reconocimiento. Esta es una regla secundaria, en el sentido de que sirve para identificar a otras reglas del sistema. La validez de las reglas identificadas por la regla de reconocimiento no depende de que efectivamente sean aplicadas por los tribunales, pero la regla de reconocimiento existe si, y solo si, es practicada. Su existencia es una cuestión de hecho. Esto significa que existe en la medida en que los funcionarios relevantes de 
una comunidad la usen para identificar las normas del sistema. Como toda regla social, requiere que se verifique un aspecto externo, dado por el efectivo uso de esta regla, y un aspecto interno, dado por la aceptación de que el patrón de conducta prevaleciente constituye un estándar de comportamiento legítimo o justificado ${ }^{18}$. De esta manera, la teoría de Hart, señala Shapiro, es claramente positivista. La existencia de la regla de reconocimiento es una pura cuestión de hechos sociales ya que "las reglas son prácticas sociales" 19 .

Como señala Shapiro, definir las reglas como prácticas es simplemente un error de categoría. Las reglas son entidades abstractas y las prácticas son hechos que tienen lugar espaciotemporalmente. Tal vez Hart quiera debilitar su tesis, sugiere Shapiro, admitiendo que las reglas no pueden ser reducidas a prácticas, no obstante, estas últimas necesariamente generan reglas. En otros términos, la versión debilitada diría que la instanciación de una práctica es condición suficiente de la generación de una regla social. Lamentablemente, esta posición tampoco es sostenible.

Este aspecto de la teoría ya había sido criticado por Raz, para quien las condiciones de existencia de las reglas sociales especificadas por Hart son sobreincluyentes. Según Raz, no permiten distinguir entre dos tipos de prácticas bien diferentes: la práctica de actuar por razones generales y la práctica de actuar siguiendo reglas. No siempre que se actúa por razones generales se actúa guiado por una regla ${ }^{20}$. Piénsese en un partido de fútbol. Un espectador que concurre al campo podrá notar que cuando un jugador distinto del arquero toca el balón con la mano el árbitro sanciona una falta y otorga un tiro libre al equipo contrario. Cualquier desviación de este patrón de conducta genera fuertes críticas. Asimismo, podrá observar que cuando un defensor se encuentra presionado cerca de su área siempre rechaza el balón hacia fuera, o intenta salir jugando por la banda, pero casi nunca rechaza el balón hacia dentro. En este caso, las desviaciones del patrón también generan

\footnotetext{
18 Véase Hart, H. L. A., op. cit., capítulos V y VI.

19 Shapiro, S., Legalidad, op. cit., p. 117.

${ }^{20} \mathrm{Raz}$, J., Practical reasons and norms, Oxford, Oxford University Press, 1990, p. 55.
} 
críticas. Sin embargo, aunque existe una regla que ordena sancionar un tiro libre cuando algún jugador distinto del arquero toca el balón con la mano, no existe ninguna regla que disponga que los defensores deban rechazar el balón hacia fuera del área ${ }^{21}$. En ambos casos existe un patrón de conducta (aspecto externo) y críticas ante la desviación (aspecto interno), pero solo en el primer caso los participantes están siendo guiados por una regla. En el segundo caso los individuos obran siguiendo lo que podría denominarse un juicio normativo generalizado. Estos juicios no son más que buenas razones, en general, para realizar ciertas acciones. Una diferencia fundamental entre las reglas y los juicios normativos generalizados es que las primeras serían razones independientes de su contenido, mientras que los segundos no $^{22}$.

Shapiro considera que existe otra forma de salvar la teoría de Hart. Atento a la objeción de Raz, advierte que tal vez no todas las prácticas generen reglas pero sí algunas de ellas. De todas maneras, entiende que a menos que se especifiquen las condiciones que deben satisfacer las prácticas para generar reglas sociales, la teoría hartiana será incapaz de resolver la paradoja de la autoridad. La manera más promisoria de enmendar la teoría de las reglas como práctica, sugiere luego, está dada por la idea de que la regla de reconocimiento es una convención de coordinación que resuelve el problema recurrente de establecer una estructura de autoridad. Eventualmente, rechaza esta interpretación porque "restringe indebidamente los tipos de razones que los funcionarios pueden tener para aceptar la regla de reconocimiento"23. Dado que una convención de coordinación solo existe cuando los participantes toman el patrón de comportamiento como una razón para hacer lo que hacen los demás, sería imposible la alienación general de los funcionarios. Semejante teoría hace inconcebible un sistema en el cual los funcionarios son indiferentes a la manera en que se comportan sus colegas y solo hacen su trabajo para cobrar su salario a fin de $\mathrm{mes}^{24}$.

${ }^{21}$ El ejemplo original, referido al cricket, está tomado de Warnock, G. J., The Object of Morality, London, Methuen, 1971, pp. 45-46.

22 Shapiro, S., "On Hart's Way Out", Legal Theory, 4 (4), 1998, pp. 469-507, en p. 493.

${ }^{23}$ Shapiro, S., Legalidad, op. cit., p. 150. 
Hay otra alternativa obvia que Shapiro curiosamente no analiza. Hart concede que un patrón de conducta y un actitud crítico-reflexiva es insuficiente para afirmar que existe una obligación, en tanto las reglas de etiqueta también tienen estos dos componentes, pero no diríamos que imponen obligaciones; al menos, no diríamos que imponen obligaciones conforme con el uso característico del término. De ahí que Hart agrega que cuando una regla impone una obligación la exigencia general para la observancia es constante y la presión contra quienes se desvían o amenazan con desviarse es sustancial. Además, difícilmente en una sociedad se pueda considerar que una acción es obligatoria si no se juzga que su realización es importante para el mantenimiento de la vida en comunidad ${ }^{25}$. Estas condiciones permiten distinguir los juicios normativos generalizados de las reglas que imponen deberes. Es verdad que la referencia de Hart a la importancia de la acción obligatoria para la vida de la comunidad es un tanto vaga. Pero esto mismo puede explicarse recurriendo a la idea de razones excluyentes (o perentorias, en los términos del propio $\mathrm{Hart}^{26}$ ). Así, las prácticas que necesariamente generan reglas sociales son aquellas en las que los individuos tienen una actitud determinada hacia el patrón de conducta: lo toman como una razón de primer orden para comportarse tal como establece el patrón y como una razón excluyente, es decir, como una razón para no actuar sobre la base de al menos algunas otras razones de primer orden en conflicto.

Creo que esta interpretación raziana de Hart permite definir el tipo de prácticas capaces de superar la paradoja de la autoridad ${ }^{27}$. Si esto es

${ }^{25}$ Hart, H. L. A., op. cit., pp. 86-87 (107-109).

${ }^{26}$ Hart, H. L. A., "Commands and Authoritative Reasons", en Essays on Bentham, Oxford, Clarendon Press, 1982. Las diferencias entre los conceptos de razón perentoria y razón excluyente no son relevantes para el argumento aquí presentado. Para un buen comentario al respecto, veáse Himma, K. E., "Inclusive Legal Positivism", en Coleman, J. L., Shapiro, S., Himma, K. E., Oxford Handbook of Jurisprudence and Philosophy, Oxford, Oxford University Press, 2002, pp. 152-153.

${ }^{27}$ Correspondería señalar todavía que la interpretación raziana solo puede dar cuenta de las reglas que imponen deberes, pero no de las reglas constitutivas, por ejemplo. Sin embargo, esto no tiene por qué inquietar a Shapiro dado que para él la regla de reconocimiento es una regla de deber, es decir, que impone a los funcionarios la 
así, unas de las razones para abandonar la teoría sustantiva de Hart, y avanzar en la comprensión del fenómeno jurídico mediante la idea de planes, pierde su fundamento.

La segunda razón por la cual Shapiro cree que la teoría de Hart debe ser abandonada tiene que ver con lo que él denomina "el desafío de Hume". El problema para Hart es que, de acuerdo con la teoría de las reglas como práctica, una vez que se dan ciertos hechos es posible constatar la existencia de la regla de reconocimiento y, por consiguiente, afirmar la validez de las normas primarias identificadas por ella. Las normas primarias imponen deberes y confieren derechos, y su validez justifica juicios como los siguientes: en Xanadú, todos los empleados deben guardar silencio cuando Kane duerme la siesta. Dada la imposibilidad lógica de inferir lo que debe ser a partir de lo que es, esperaríamos que la teoría de Hart evitase derivar juicios normativos a partir de juicios descriptivos. Pero eso es exactamente lo que ocurre cuando de afirmar (1) la existencia de un hecho (por ejemplo, que ciertos individuos en la comunidad aceptan que aquello ordenado por Kane debe ser obedecido) se pasa a afirmar (2) la validez de una norma (en Xanadú los empleados deben guardar silencio cuando Kane duerme la siesta; asumiendo que Kane haya ordenado eso).

Para evitar la infracción a la ley de Hume, Shapiro sugiere que Hart sea entendido como un expresivista. Es incuestionable que la existencia de la regla de reconocimiento depende de ciertos hechos sociales. Así y todo, es posible mantener dos actitudes muy diferentes frente a esos hechos. Es posible tener una actitud teórica y, por tanto, los enunciados formulados son descriptivos, o tener una actitud práctica, en cuyo caso los enunciados formulados son normativos. No describen la existencia de normas sino que expresan un compromiso práctico con hechos descriptivos. El individuo expresa su compromiso con tratar estos hechos de cierta manera. En terminología más usual, expresan la

obligación de aplicar las normas que satisfacen ciertos criterios. Véase Shapiro, S., Legalidad, op. cit., p. 121. Además, Shapiro mismo en un artículo anterior consideró que esta interpretación resuelve los problemas de sobreinclusión de la teoría de Hart. Véase Shapiro, S., "On Hart's Way Out”, op. cit., pp. 493-494. 
aceptación de una regla como estándar de conducta legítimo. Nótese que las condiciones de existencia del derecho no incluyen más que hechos sociales, pero los juicios relativos a derechos y deberes, o a la validez de normas primarias, expresan una orientación práctica hacia ellos. De esta forma, el patrón de inferencia seguido por el esquema hartiano es siempre normativo, ya que los juicios normativos se derivan de un compromiso normativo. La ley de Hume es respetada. Sin embargo, esto implica que el teórico que se niega a aceptar el punto de vista interno nunca puede determinar lo que exige el derecho porque su razonamiento es siempre descriptivo ${ }^{28}$.

Esta lectura expresivista de Hart respeta la ley de Hume, pero es muy problemática en tanto el "hombre malo" (bad man) de Holmes puede llevar adelante un razonamiento jurídico sin comprometerse con el punto de vista interno ${ }^{29}$. El hombre malo, que obedece el derecho solo por razones prudenciales, es capaz de redescribir sus juicios en terminología jurídica. En lugar de decir que está obligado a pagar impuestos, por ejemplo, puede afirmar que jurídicamente tiene la obligación de pagarlos. Shapiro cree que siempre es posible redescribir el contenido del derecho empleando lenguaje normativo, sin aceptar al mismo tiempo la regla de reconocimiento. De hecho, sería muy extraño que los únicos capaces de acceder al contenido del derecho fueran quienes lo aceptan. Los profesores con frecuencia describen el contenido de otros sistemas jurídicos con fines comparativos sin asumir el punto de vista interno respecto de cada uno de ellos. En contraste, la versión expresivista de Hart supone que solo quienes aceptan la regla de reconocimiento pueden hacer esto. Por lo tanto, la teoría no puede dar cuenta del hombre malo, que realiza razonamientos jurídicos y redescribe el sistema con precisión. En breve, Shapiro argumenta que el hombre malo, en la medida en que es malo, no asume una actitud práctica respecto de la regla de reconocimiento, pero de todas formas

${ }^{28}$ Shapiro, S., Legalidad, op. cit., p. 150 y ss.

${ }^{29}$ Ibidem, p. 153. 
es capaz de derivar juicios normativos a partir de juicios descriptivos; y ello constituye una violación de la ley de Hume ${ }^{30}$.

Esta crítica probablemente sea el punto más decepcionante del libro de Shapiro. Todo el argumento descansa sobre una lectura expresivista de Hart que nos lleva a conclusiones tremendamente implausibles. Dadas las consecuencias de esta reconstrucción, ¿no deberíamos descartar de inicio la lectura expresivista que Shapiro propone? ¿Hay alguna interpretación alternativa para evitar que Hart infrinja la ley de Hume? En mi opinión, hay al menos dos posibilidades, ambas rastreables en última instancia a afirmaciones explícitas de Hart, y curiosamente ignoradas por Shapiro.

La primera posibilidad es entender que los juicios del hombre malo, al igual que los del teórico, se realizan desde el punto de vista externo moderado. A fin de determinar lo que exige el derecho de una determinada comunidad se requiere indagar en qué normas los funcionarios creen que brindan razones para la acción. Luego, uno podrá descubrir qué deberes y derechos creen que tienen los propios funcionarios y el resto de los ciudadanos. El patrón de inferencias siempre es descriptivo-descriptivo. Los enunciados sobre validez, derechos y deberes nunca son genuinamente normativos, sino descriptivos de creencias y actitudes de los funcionarios del sistema ${ }^{31}$.

La segunda manera de entender a Hart consiste en incorporar la noción de enunciados normativos no-comprometidos (detached normative statements) propuesta por Raz, y que el propio Hart acepta como un buen complemento de su clasificación entre enunciados externos

${ }^{30}$ Ibidem, pp. 152-153.

${ }^{31}$ Esta alternativa encuentra apoyo en el "Postscript" a la segunda edición de The Concept of Law. Allí Hart responde a Dworkin que la existencia de una regla social, como la regla de reconocimiento, no está condicionada a que haya razones suficientes para conformarse a la regla sino a que los participantes crean que existen tales razones. Véase Hart, H. L. A., "Postscript", en The Concept of Law, op. cit., p. 257 (35). [N. E.: no se ha consolidado aún una traducción canónica de las notas manuscritas de Hart, que Joseph Raz y Penelope Bulloch incluyeron como "Postscript" en la segunda edición de The Concept of Law (pp. 238-276). A los fines de lograr uniformidad se cita en la traducción de Rolando Tamayo y Salmorán: Hart, H. L. A., Post scríptum al concepto de derecho, México, UNAM, 2000. En paréntesis se indican las páginas correspondientes a la traducción]. 
acerca del derecho y enunciados internos formulados por los participantes $^{32}$. Según Raz, los enunciados normativos no-comprometidos se refieren a los derechos y deberes que tienen las personas. No se trata de afirmaciones acerca de creencias, actitudes o patrones de conducta, sin embargo carecen de la fuerza que ordinariamente tienen los enunciados normativos. Por ello, pueden ser proferidos sin comprometer al hablante con lo que expresan; solo describen una situación jurídica tal como es vista desde el punto de vista de quien acepta las normas como legítimas $^{33}$. En esta línea, el hombre malo bien puede razonar jurídicamente describiendo el punto de vista del derecho. Es solo desde el punto de vista del derecho que él tiene la obligación de pagar impuestos, o el derecho de votar en las elecciones generales. Su patrón de razonamiento no es descriptivo-normativo, sino siempre descriptivo, con lo cual la ley de Hume es respetada.

En conclusión, a diferencia de Hart, que intentó presentar la mejor versión posible de la teoría de Austin a fin de criticarla luego, la sofisticación que hace Shapiro de la teoría de Hart la hace implausible de inicio. Por esta razón, el argumento que ofrece Shapiro para dejar atrás la teoría de Hart y avanzar en su concepción del derecho como plan social no resulta a fin de cuentas convincente. Pese a todo, en lo que sigue argumentaré que la teoría de Shapiro ofrece una comprensión más amplia que la tradicional del fenómeno jurídico e ilumina una gran cantidad de aspectos que a menudo pasan inadvertidos para la mayoría de los filósofos del derecho. Continuaré en la siguiente sección describiendo algunos puntos esenciales de la teoría de Shapiro. El lector familiarizado con ella puede prescindir de esta sección.

32 Véase Hart, H. L. A., "Legal Duty and Obligation", en Essays on Bentham, Oxford, Clarendon Press, 1982, pp. 154-155.

33 Véase Raz, J., The Authority of Law, Oxford, Oxford University Press, 1979, p. 153; Raz, J., Ethics in the Public Domain, Oxford, Oxford University Press, 1996, p. 270. 


\section{La concepción del derecho como plan social}

La tesis central de Shapiro es que el derecho es una forma de planificación social. Las instituciones jurídicas planifican para la comunidad sobre la cual pretenden autoridad. Esto significa que prescriben lo que los individuos pueden o no hacer, es decir, establecen pautas de comportamiento para guiar la conducta de los ciudadanos, e identifican a quienes tienen la facultad de crear nuevas pautas o alterar las existentes. Las normas jurídicas son planes generales ${ }^{34}$, o normas similares a los planes ${ }^{35}$, creados por aquellos autorizados a planificar para la comunidad; y la actividad judicial no es más que la actividad de interpretar y aplicar los planes. La planificación jurídica tiene un objetivo concreto: resolver los problemas morales que resultan imposibles de resolver, o que serían insatisfactoriamente resueltos, mediante formas de organización social alternativas ${ }^{36}$.

¿Cómo llega Shapiro a estas conclusiones? Los individuos, observa, son criaturas que planifican: diseñan, adoptan y llevan adelante planes para alcanzar sus objetivos. La razón por la que planifican es que sus objetivos y deseos son complejos y, a menudo, requieren la coordinación entre varios agentes. Además, los individuos tienen una racionalidad limitada y la deliberación caso por caso puede ser muy costosa. La adopción y ejecución de un plan es un modo de maximizar el logro de sus objetivos que se ven afectados por estas circunstancias ${ }^{37}$.

En el caso de las actividades colectivas, el éxito del grupo depende de que cada individuo haga su parte. Esto requiere una coordinación que resulta difícil de lograr por medio de la improvisación. En algunos

${ }^{34}$ Shapiro define a los planes como "entidades proposicionales abstractas que exigen, permiten o autorizan a los agentes a actuar, o no actuar, de ciertas maneras en ciertas circunstancias". En este sentido, los planes son normas, pero no toda norma es un plan. Las normas morales, por ejemplo, existen porque son válidas, no porque alguien las haya adoptado. Véase Shapiro, S., Legalidad, op. cit., pp. 169-170.

35 Por "normas similares a los planes" Shapiro se refiere a las costumbres. Las normas consuetudinarias no son planes, pero cumplen las mismas funciones. Véase Ibidem., p. 184.

36 Ibidem, pp. 220 y 265.

$196 \quad{ }^{37}$ Ibidem, pp. 163-164. 
contextos, en los que las partes se conocen perfectamente y están vinculadas por fuertes lazos de confianza, la improvisación puede funcionar. Cuando estas condiciones no se dan, surge la necesidad de brindar una guía de conducta. Por lo general, aunque el objetivo del grupo sea claro, existirán varias maneras de lograrlo, y ello hace que lo que cada individuo debe hacer, es decir, la conducta que debe realizar como parte de la actividad común, dependa de lo que harán lo otros. Así, la planificación parece ser la única manera de llevar adelante la empresa colectiva en condiciones de incertidumbre respecto de qué acciones realizarán los demás. Todos estos problemas son especialmente importantes cuando las actividades comunes son complejas, controvertidas o requieren soluciones arbitrarias ${ }^{38}$. Así, afirma Shapiro, los planes ofrecen una solución al cumplir una función de control sobre el comportamiento de las personas ${ }^{39}$.

En lo que hace al derecho, nótese que cualquier conjunto de individuos para vivir en sociedad necesitará resolver una serie de problemas que Shapiro califica como morales. Estos incluyen la regulación de la propiedad, los contratos, los niveles de diligencia exigibles, la presión tributaria adecuada, los límites del poder público y la legitimidad de la coerción estatal, entre muchos otros. Las sociedades modernas son incapaces de resolver estos problemas eficientemente mediante otras formas de planificación social o la coordinación espontánea. Dado que estos problemas morales son numerosos y requieren soluciones complejas, controvertidas o arbitrarias, las sociedades modernas se hallan en lo que Shapiro denomina las "circunstancias de la legalidad" 40 . E1 propósito fundamental del derecho, agrega luego, es solucionar las deficiencias morales que se producen en estas circunstancias. Esto es lo que Shapiro presenta como la Tesis del fin moral del derecho ${ }^{41}$. En este punto, Shapiro profundiza el argumento de Raz, de acuerdo con el

${ }^{38}$ Una solución es arbitraria cuando existen alternativas igualmente adecuadas. Esta idea tiene su origen en Lewis, D., Convention. A Philosophical Study, Cambridge, Mass., Harvard University Press, 1969, p. 70.

${ }^{39}$ Shapiro, S., Legalidad, op. cit., p. 174.

${ }^{40}$ Ibidem, p. 217.

41 Ibidem, p. 265. 
cual incluso una sociedad de ángeles necesitaría derecho para resolver algunos problemas de coordinación ${ }^{42}$. En términos de Shapiro, incluso individuos bienintencionados, de buena fe, necesitarían una guía de conducta para saber cómo deben comportarse frente a los problemas morales en las circunstancias de la legalidad ${ }^{43}$.

Es importante señalar que la tesis del fin moral no atribuye al derecho ningún fin sustantivo concreto. El derecho es un medio para resolver cualquier problema moral que se desee resolver. En este sentido, el problema que aborda necesariamente es de segundo orden, pues consiste en determinar cómo deben resolverse los conflictos morales. Una respuesta parcial a la pregunta de la identidad, entonces, es que lo que hace que el derecho sea derecho es que tiene el propósito de establecer un mecanismo para resolver los problemas morales que no pueden ser resueltos eficientemente por las costumbres, las tradiciones, el consenso, la persuasión o las promesas ${ }^{44}$. La actividad jurídica, al igual que cualquier plan, logra su objetivo guiando, organizando y controlando la conducta individual y grupal. A la vez, permite a los agentes reducir los costes de deliberar, negociar y acordar; incrementa la predictibilidad del comportamiento y soluciona los problemas que generan la falta de información, la incapacidad para tomar decisiones perfectamente racionales o el mal carácter ${ }^{45}$. Por supuesto, el derecho es falible y, por ello, es posible que las respuestas jurídicas sean moralmente insatisfactorias ${ }^{46}$.

Ahora bien, los factores que hacen que los planes sean más necesarios para resolver los problemas morales de la comunidad también hacen que sean más difíciles de implementar. Mientras más numeroso

42 Véase Raz, J., Practical Reasons and Norms, op. cit., pp. 159-160.

${ }^{43}$ Shapiro, S., Legalidad, op. cit., p. 222.

44 Ibidem, pp. 267-268. Como digo en el cuerpo principal, esta es solo una parte de la respuesta de Shapiro a la pregunta de la identidad. El derecho, además de tener esta misión moral, es una organización compulsiva y que se autovalida; esto último significa que hace cumplir sus normas sin demostrar su validez ante organizaciones superiores (véase Ibidem, p. 279).

45 Ibidem, pp. 250-251.

$198 \quad 46$ Ibidem, p. 266. 
sea el grupo más complejo será acordar un plan común. En estas condiciones florecen las ideas de delegación y jerarquía. Las comunidades delegan la planificación en ciertos individuos, cuya identificación es funcional, no nominal. Estos individuos, los funcionarios del sistema, se encargarán de adoptar un plan para la comunidad. Otros individuos, por su parte, tendrán a su cargo la aplicación de los planes. El plan que establece esta división del trabajo es un plan común para la planificación social. Su objeto es solucionar el problema de cómo planificar para la comunidad cuando ella más necesita de planes pero se encuentra en las peores condiciones para adoptarlos y aplicarlos. Este plan, que Shapiro denomina plan maestro, es el fundamento del sistema jurídico ya que, según entiendo, cumple en la concepción del derecho como plan el mismo rol que la regla de reconocimiento cumple en la teoría de Hart ${ }^{47}$. El plan maestro y todos los planes o normas similares a los planes adoptados y aplicados por el grupo social conforman el sistema jurídico de la comunidad ${ }^{48}$.

El plan maestro es un plan común, pero no es el plan de la comunidad en su conjunto. Quienes comparten el plan de planificar para la comunidad son los planificadores sociales; son ellos quienes aceptan el plan. Dicho en otros términos, los funcionarios aceptan el plan maestro que guía, organiza y controla su conducta conjunta de planificar para los demás. Su trabajo conjunto hace que los funcionarios tengan un plan común y, por ello, que sean miembros de un mismo sistema jurídico ${ }^{49}$. Sin embargo, afirmar que los funcionarios tienen autoridad jurídica supone afirmar algo más que el hecho de que están autorizados por el plan maestro para adoptar planes. Se requiere además que sean capaces de disponer el cumplimiento por parte del resto de la comunidad. Esta disposición puede lograrse de cualquier manera, lo que incluye la amenaza de sanción. Recién cuando se dan estos dos elementos, la autorización y la capacidad de motivación, puede

\footnotetext{
47 Ibidem, pp. 212-214.

48 Ibidem, pp. 260 y 279.

49 Ibidem, pp. 259-260.
} 
sostenerse que los funcionarios tienen autoridad jurídica, que tienen la habilidad de planificar para otros ${ }^{50}$.

Si nos preguntamos por qué Rex tiene autoridad jurídica en la comunidad S, diríamos que Rex está autorizado por el plan maestro para planificar para los individuos de $\mathrm{S}$ y, además, que tiene la capacidad de disponerlos a cumplir con los planes, valiéndose de amenazas de sanción o cualquier otro método de motivación. El plan maestro, a su vez, existe porque los funcionarios, entre los que se cuenta Rex, lo aceptan. Pero, ¿cómo han obtenido la autoridad de adoptar el plan cuyo contenido es que Rex habrá de planificar para el resto? Aquí la palabra "autoridad" no debe ser entendida como autoridad jurídica; en lugar de ello, se refiere a la autoridad que todos los individuos tienen para adoptar planes por el mero hecho de ser criaturas que planifican. Las normas de la racionalidad instrumental los facultan a adoptar planes. Por esta misma razón, los funcionarios tienen la facultad de adoptar el plan maestro. Las normas de la racionalidad no son planes, no han sido creadas por ninguna autoridad. El único fundamento del plan maestro está en la racionalidad instrumental, que sirve de sostén normativo a todo el sistema jurídico. En síntesis, la autoridad jurídica es posible porque ciertos agentes son capaces de crear y compartir un plan para planificar y de motivar a otros a cumplir su plan ${ }^{51}$. De esta manera Shapiro responde a la paradoja de la autoridad.

La concepción del derecho como plan es una teoría positivista, en tanto la existencia del derecho puede ser determinada mediante la observación social. El teórico no debe más que constatar el hecho de que los funcionarios del sistema han adoptado un plan para resolver las deficiencias morales de las circunstancias de la legalidad. La autoridad jurídica de los órganos no depende de ninguna consideración moral, sino solo de que los funcionarios hayan aceptado un plan que autoriza a ese órgano a planificar para la comunidad y que requiere deferencia hacia él. De esto se sigue que para crear o hacer funcionar un sistema jurídico no es necesario que los funcionarios tengan legitimidad moral 
para imponer obligaciones y conferir derechos. Solo se requiere que tengan la habilidad de planificar. Por todo esto, la teoría de Shapiro satisface la tesis de las fuentes sociales, ya que no hay plan sin hechos sociales y no hay derecho sin planes, y la tesis de la separabilidad entre el derecho y la moral, ya que el mérito de los planes es una cuestión que nada tiene que ver con sus condiciones de existencia.

A muy grandes rasgos esta es la visión que Shapiro tiene del derecho. Su respuesta a la pregunta de la identidad puede superar el desafío de Hume ya que los enunciados sobre la validez de las normas se refieren a la concepción moral reflejada en el sistema jurídico, a lo que cada uno tiene el deber moral de hacer desde el punto de vista del derecho. Este punto de vista es el de la teoría normativa que sostiene que las normas del sistema son legítimas y moralmente obligatorias. El teórico cuando formula enunciados de validez, o acerca de los derechos y deberes de los individuos, simplemente describe esta perspectiva normativa. La concepción del derecho como plan también resuelve, como se ha visto, la paradoja de la autoridad: la autoridad jurídica es creada por normas (planes), pero no todas las normas son creadas por individuos con autoridad jurídica. El fundamento del sistema es el plan maestro, cuya existencia no depende de que haya sido creado por un grupo de individuos con autoridad jurídica para hacerlo, sino de que sea adoptado y aplicado por algunos miembros del grupo.

\section{La teoría del derecho como plan social y las explicaciones externas}

Quiero argumentar aquí que la teoría de Shapiro puede ser interpretada de dos maneras diferentes. Puede ser vista como una teoría interna o como una teoría externa. Como teoría interna continúa la tradición hartiana al insistir en que uno de los criterios para evaluar las teorías jurídicas es que da sentido al discurso de los participantes. En la sección anterior, hemos visto cómo Shapiro ofrece una respuesta para cada uno de los interrogantes usuales de la teoría del derecho. Es capaz de encontrar un fundamento último para las normas del sistema, dado 
por el plan maestro, que también explica su unidad. A la vez, puede dar cuenta de nuestras intuiciones respecto de la autoridad jurídica $\mathrm{y}$, aunque mi breve reconstrucción no permite apreciarlo totalmente, también es capaz de acomodar todas las verdades obvias que enuncia al comienzo de su libro.

Mas la teoría de Shapiro también admite una lectura externa; en particular, se trataría de una típica explicación funcional, cuyas raíces pueden rastrearse hasta la obra de Emile Durkheim.

Las explicaciones externas parten de la idea de que los significados que los individuos atribuyen a ciertas instituciones como la familia, la religión o el derecho, entre otras, no muestran más que una parte superficial de la realidad social. Durkheim pensaba que es natural que los individuos formen algunos conceptos a fin de reglamentar su vida, pero es un error quedarse con estas nociones que nos resultan más cercanas que las realidades a las cuales se corresponden. La supresión de esta realidad en la labor del investigador es una tendencia que debe ser combatida, porque los individuos tienden a convertir estas nociones superficiales en materia de especulación carente de valor científico ${ }^{52}$.

En este sentido, la teoría de Austin también puede ser interpretada como externa. En general, las críticas hartianas -a las que Shapiro adhiere-suponen que este modelo explicativo hace ininteligible el discurso de los participantes, el modo en que piensan y argumentan en términos de reglas, y la manera en que las utilizan para guiar su comportamiento. Pero si uno interpreta la teoría de Austin como una explicación externa, estas críticas están desencaminadas, ya que su teoría pretendería mostrar que el derecho, más allá de la ornamentación conceptual de los participantes, no es más que un conjunto de actos de fuerza. No importa que los participantes sientan tener una obligación o ser titulares de derechos, lo más relevante para entender el fenómeno jurídico es la figura de un soberano que emite órdenes respaldadas por amenaza de sanción y que es habitualmente obedecido por la mayor parte de la población. No hay nada mágico detrás del derecho que nos

52 Durkheim, É., Las reglas del método sociológico, México, Fondo de Cultura Económica, [1895], 1986, p. 53. 
permita distinguirlo de cualquier otro uso organizado de la fuerza. Por ello, el teórico que se centra en el punto de vista interno se aleja de la verdadera naturaleza del derecho. La paradoja de la autoridad, en este sentido, sería para Austin un pseudoproblema: solo desde el punto de vista interno las autoridades tienen derecho a mandar en virtud de alguna otra norma que les confiere esa potestad.

Pese a lo anterior, para una explicación externa los conceptos con los que los individuos interpretan la realidad no son totalmente inútiles, aunque solo sirven de indicador ${ }^{53}$. Limitarse a la interpretación de las categorías superficiales constituye, en este sentido, una clase de conformismo teórico, científicamente reprobable. Para Durkheim, la realidad se hace inteligible cuando el investigador logra desentrañar las necesidades sociales que satisfacen las instituciones que ordenan la vida de la comuni$\mathrm{dad}^{54}$. Una vez que se asume esta perspectiva, el mejor modo de dar cuenta de la realidad social es por medio de una explicación funcional.

La explicación funcional se adecúa a los parámetros de las explicaciones que corrientemente se ofrecen en la biología. En este campo de conocimiento, las investigaciones apuntan a descubrir por qué tiene lugar un proceso (¿por qué ocurre la fotosíntesis?), qué explica la presencia de algún órgano en ciertas especies (¿por qué los peces tienen branquias?) o de algún rasgo o característica (¿por qué tienen manchas los leopardos?). Las respuestas en todos los casos tienen que ver con la función que cumple un determinado ítem (el proceso, el órgano o la característica) en un ecosistema u organismo. Así, 'la función del corazón es hacer circular la sangre', 'la función de los pulgares de los pies es contribuir a que el individuo mantenga el equilibrio', 'la función del hígado es segregar bilis', son todas proposiciones que tienen la forma de una explicación funcional. En las ciencias sociales la idea de organismo es reemplazada por la de sistema social, y aquello de lo que se predica la función, en lugar de ser un órgano o un rasgo, puede ser una práctica o institución. Ejemplos clásicos en este campo son las explicaciones funcionales de la religión o de la familia: 'la religión tiene 
por función lograr una mayor cohesión social entre los miembros de una comunidad' o 'la familia cumple la función de proteger a los hijos y entrenarlos de modo que se maximice su aptitud para la supervivencia' son proposiciones que pretenden explicar ciertas instituciones por la función que cumplen en un sistema social.

En la típica explicación funcional, las funciones que cumple una institución en un determinado sistema social son opacas a los participantes, pero no tienen por qué serlo. Los desarrollos teóricos son parte de la vida en sociedad, por lo tanto, es esperable que las funciones descubiertas por los investigadores, luego de algún tiempo, pasen a ser conocidas por el resto de los individuos. Pese a todo, la explicación sigue siendo funcional dado que no depende de la autocomprensión de los miembros de la comunidad, sino que apunta a los efectos beneficiosos producidos por una institución o práctica. En este sentido, no sostengo una versión de la explicación funcional tan exigente como la de Elster, para quien es una parte esencial de este tipo de teorías que el efecto beneficioso de la institución o práctica sea: (a) no intencional para los miembros de la comunidad; (b) no reconocido por los actores de la comunidad o, al menos, que les sea desconocido cómo es que sus acciones producen el efecto beneficioso ${ }^{55}$. La razón por la que Elster incluye estas condiciones, entre otras, como parte de una explicación funcional es que si los individuos fuesen conscientes de los efectos beneficiosos de sus acciones o si la obtención de estos efectos fuese intencional, la explicación pasaría a ser interna.

Sin embargo, creo que tienen razón quienes critican este modelo ${ }^{56}$. La explicación podría seguir siendo funcional siempre que el efecto beneficioso sea una consecuencia evidente de una acción intencional pero los individuos no pretendan producirlo realizando la acción a la que se adscribe la función. Si el reconocimiento de los beneficios que produce la institución es causalmente inerte, no se advierte por qué la

55 Elster, J., Ulysses and the Sirens. Studies in rationality and irrationality, revised edition, Cambridge, Cambridge University Press, 1984, p. 28.

${ }^{56}$ Schwartz, J., "Functional Explanation and Metaphysical Individualism", Philosophy of Science, 60 (2), 1993, pp. 278-301, en pp. 281-282. 
explicación dejaría de ser funcional; el mero hecho de que luego de un tiempo los participantes de la práctica tomen conciencia de los efectos beneficiosos de sus instituciones o patrones de conducta no atenta contra la idea de que una explicación sea funcional. Por ejemplo, la explicación funcional de la religión como un modo de cohesión social podría seguir siendo funcional y no interna o conceptual aunque, después de algún tiempo, todos los participantes de las prácticas religiosas conociesen los efectos beneficiosos, pero no buscados, de la religión. La estructura de la explicación se mantendría siempre que este conocimiento fuese causalmente irrelevante para el mantenimiento de la práctica religiosa; es decir, siempre que el hecho de conocer la función no afectase las razones de los participantes para sostener una religión. Esta idea puede resumirse señalando que las explicaciones funcionales, a diferencia de las explicaciones basadas en razones o propósitos, no presuponen la agencia de los individuos ${ }^{57}$. Sin embargo, es posible que una práctica evolucione y adopte como propósito lo que previamente era una función. Por ejemplo, una sociedad altamente desarrollada podría llegar a advertir que su práctica religiosa se basa en creencias falsas, pero aun así preservarla como tradición por su valor en términos de cohesión social. En este caso, la explicación funcional externa sería reemplazada por una intencional interna.

A esta altura ya podrá apreciarse cuál es mi argumento. Creo que, para alguien que pretende desentrañar la naturaleza del derecho mediante un análisis conceptual, Shapiro presta una atención inusual a los beneficios sociales generados por el sistema jurídico. Los planes tienen una infinidad de ventajas comparativas respecto de otros modos de ordenación social del comportamiento. De hecho, las primeras observaciones que realiza Shapiro sobre la planificación apuntan a que es una forma de superar todos los inconvenientes derivados de la racionalidad limitada y de los costes de deliberar. Por supuesto, luego de una reflexión adecuada los individuos podrían aceptar que estas son excelentes razones para planificar, pero dado que la planificación tiene

57 Véase Brown, R., Explanation in Social Science, Chicago, Aldine Publishing Company, 1963, p. 109. 
lugar con independencia del reconocimiento sus múltiples ventajas, la explicación puede ser entendida como parcialmente externa.

En igual sentido, al analizar las actividades colectivas, Shapiro advierte que los grupos enfrentan dificultades adicionales, relacionadas con que algunos de los problemas de vivir en sociedad requieren soluciones complejas, controvertidas o arbitrarias. En esas circunstancias, los planes colectivos permiten controlar y coordinar la conducta de los miembros del grupo y dar una mayor previsibilidad a sus acciones. Shapiro explícitamente declara que la función de los sistemas jurídicos es superar las deficiencias de las formas alternativas de planificación en las circunstancias de la legalidad. Las instituciones jurídicas deberían permitir a las comunidades superar las dificultades de la vida social que no pueden ser resueltas por otros mecanismos no jurídicos, como la interacción espontánea, la improvisación, los acuerdos privados, etcétera. En la misma línea interpreta a la jerarquía como un avance tecnológico fundamental para las sociedades modernas, ya que permiten planificar cuando la deliberación colectiva es imposible, o planificar de modo más eficiente, cuando siendo fácticamente posible sus costes resultan prohibitivos.

Shapiro también cree que todas estas funciones explican por qué consideramos valioso el derecho. Pero en realidad no explican esto. Las razones por las que de hecho se valora el derecho varían de comunidad en comunidad, son una cuestión contingente. Algunas comunidades pueden considerarlo valioso por razones mitológicas, otras por razones religiosas, otras por razones nacionalistas (porque es su derecho), etcétera. Pero vista como parte de una explicación funcional, la afirmación de Shapiro es que los beneficios que produce el derecho deberían contar como buenas razones para que todas las comunidades lo valoren. Estas son razones objetivas, siempre que se adhiera a una teoría subyacente sobre lo que es objetivamente valioso para todas las comunidades. La coordinación y el control de la conducta de los miembros del grupo, y la eficiencia de la planificación respecto de otras formas de organización social son beneficiosos para el grupo desde un determinado punto de vista: el del sistema que se estudia. La teoría de la evolución natural supone que la supervivencia de las especies es algo beneficioso 
para ellas. Sin este presupuesto, las explicaciones funcionales de las manchas de los leopardos, de los cromatóforos de los cefalópodos, etcétera, carecen de fundamento. La atribución de función no se limita a señalar qué hace cada ítem en el sistema en el cual está alojado, sino que pretende esclarecer de qué manera aquello que hace es beneficioso para el sistema. Del mismo modo, la interpretación funcional de la teoría de Shapiro requiere asumir que la posibilidad de diseñar e implementar de manera eficiente una respuesta para los problemas morales que los individuos identifican es algo beneficioso para la comunidad.

La adscripción de función es la cuestión más controvertida en este tipo de explicaciones aplicadas a las ciencias sociales. En las ciencias naturales el problema también existe pero no genera tantas controversias. Así, adscribir al corazón la función de hacer circular la sangre requiere presuponer que los corazones usualmente hacen circular la sangre (la mayoría de ellos, pero no los defectuosos), y que esto es algo bueno para el cuerpo que los aloja, en el sentido de que contribuye al mantenimiento del organismo con vida ${ }^{58}$. En contraste con esta, las adscripciones de función como las realizadas por los partidarios del análisis económico del derecho pueden provocar fuertes reacciones. Por ejemplo, la afirmación de que la función de la responsabilidad civil es minimizar el coste de los accidentes presupone que la responsabilidad civil tiene la disposición a minimizarlos, y que la minimización es algo beneficioso para la comunidad. Ambas cosas han sido enérgicamente cuestionadas en la literatura. Pese a todo, creo que es menos discutible que la eficiencia en la toma de decisiones, o en la planificación, tiene valor para la comunidad con independencia de la teoría política que se sostenga.

Es importante mencionar que esta concepción de la explicación funcional no es la única disponible. Existen varias alternativas. Así, Wright y Millikan, cada uno a su manera, evitan la inclusión de los efectos beneficiosos al asociar la función del ítem a una cierta etiología

58 Véase McLaughlin, P., What Functions Explain. Functional Explanation and Self-Reproducing Systems, Cambridge, Cambridge University Press, 2001, pp. 191-204. 
o historia causal ${ }^{59}$. Tengo la impresión de que en las ciencias sociales en general, y en la comprensión de las instituciones jurídicas en particular, la historia causal es irrelevante. Cómo surgieron las instituciones puede tener interés para la historia del derecho, pero no para el análisis que aquí pretendo realizar. El proyecto que defiendo se centra en cómo opera el derecho o cuál es su contribución al desarrollo de los grupos sociales. Como señala Boorse, "los enunciados funcionales a menudo ofrecen una respuesta a la pregunta '¿por qué $x$ está presente?' (...). Sin embargo, existe otro tipo de explicación que emplea enunciados funcionales y que tiene el mismo derecho a ser llamada así. Este tipo responde la pregunta '¿cómo funciona $S$ ?" ${ }^{60}$, donde $x$ es el ítem que estamos intentando explicar, y $S$ el sistema general del cual $x$ es parte.

De manera similar, Cummins caracterizó previamente las explicaciones funcionales como una explicación de la capacidad del sistema de alcanzar un fin complejo, o de producir ciertos resultados, que apela directamente a las capacidades específicas de sus partes constitutivas. Así, de las muchas cosas que hace un ítem, su función es hacer aquello a lo que apelamos al explicar la capacidad del sistema como un todo ${ }^{61}$. El problema de esta concepción es que parece ser sobreincluyente. E1 cuerpo humano, por ejemplo, "tiene la capacidad de morir de varias enfermedades, y cada una de estas capacidades puede ser analizada de la forma en que Cummins sugiere"62. La mayoría de las personas sería reticentes a afirmar que el cáncer tiene una función dada por su contribución a la capacidad general del cuerpo de morir.

El modelo que he expuesto más arriba, aunque no puedo presentar una defensa completa aquí, evita este problema al definir la función del

59 Véase Wright, L., "Functions", The Philosophical Review, 82 (2), 1973, p. 139-168; Millikan, R. G., Language, Thought, and Other Biological Categories. New foundations for Realism, Cambridge-Mass. - London, England, The MIT Press, 1984.

${ }^{60}$ Boorse, C., "Wright on Functions", The Philosophical Review, 85 (1), 1976, pp. 70-86, en p. 75.

${ }^{61}$ Cummins, R., "Functional Analysis", The Journal of Philosophy, LXXII (20), 1975, pp. 741-765, en pp. 760-762.

${ }^{62}$ Véase Griffiths, P. E., "Functional Analysis and Proper Functions", British Journal for the Philosophy of Science, 44, 1993, pp. 409-422, en p. 411. 
ítem como su contribución a una capacidad que resulta ser beneficiosa para el sistema general. De esta manera, también intenté preservar la intuición de Durkheim, según la cual una explicación profunda del fenómeno debería intentar elucidar cómo las instituciones sociales pueden ser útiles para las comunidades que las sostienen. Por tanto, si la organización de la conducta es una necesidad vital para cualquier sociedad moderna, el derecho puede ser visto como el tipo de tecnología que la hace posible en las circunstancias de la legalidad.

\section{El punto de vista interno y la relevancia práctica de la teoría del derecho}

Shapiro podría resistir esta reconstrucción que he realizado de su teoría, por dos razones. La primera es que atenta contra las propias raíces de su proyecto. Las críticas a Austin, como ya mencioné, se fundan casi exclusivamente en que es una teoría externa y, al parecer, su objeción general contra las teorías externas es que hacen ininteligibles las prácticas jurídicas. El análisis para determinar la naturaleza del derecho se vale de ciertos conceptos explicativos, cuyos contenidos y relaciones mutuas nos permiten esclarecer los aspectos centrales de las prácticas e instituciones jurídicas. En su análisis, Hart consideraba que los conceptos centrales eran los siguientes: reglas de deber, reglas de competencia, reglas de reconocimiento, reglas de cambio, aceptación de reglas, puntos de vista interno y externo, enunciados internos y externos y validez jurídica $^{63}$. Los conceptos más importantes que Shapiro agrega en su análisis son: planes, plan maestro, punto de vista jurídico y actividad colectiva. Todos estos conceptos iluminan el modo en que opera el derecho ofreciendo una imagen de la actividad jurídica que resulta familiar para los participantes de la práctica. Nótese, además, que la noción de eficiencia o los beneficios de planificar, pese a que Shapiro los menciona permanentemente, no integran el elenco de conceptos

${ }^{63}$ Hart, H. L. A., "Postscript", op. cit., p. 240 (12). 
centrales. En sentido estricto, entonces, no parecen ser parte de su explicación interna o conceptual del derecho.

La segunda razón por la cual Shapiro podría rechazar esta interpretación externa está íntimamente relacionada con la anterior y, de alguna manera, es más importante. El problema de las explicaciones funcionales es que son incapaces de responder a la pregunta de la identidad. Nada de lo que dice Shapiro sobre los beneficios de contar con sistemas jurídicos nos permite responder a la pregunta sobre qué hace que el derecho sea derecho. Solo nos informa sobre algunas de las ventajas que pueden aprovechar las comunidades cuando abandonan las formas de coordinación menos sofisticadas y optan por una organización jurídica del comportamiento de la comunidad. Para Shapiro, la imposibilidad de responder a la pregunta de la identidad es un defecto fatal para cualquier teoría del derecho, no solo porque omite tratar el objeto principal de la reflexión filosófico-jurídica sino porque esta pregunta tiene relevancia práctica.

Explica Shapiro que a menudo no existe ninguna forma de resolver un desacuerdo acerca del contenido del derecho sin tomar una posición sobre la naturaleza del derecho en genera $1^{64}$. Seguramente, quienes sostengan que el derecho está determinado exclusivamente por fuentes sociales tendrán, en más de una ocasión, opiniones encontradas con quienes creen que su contenido depende también de consideraciones morales. Así, la teoría del derecho tal como él la concibe tiene implicaciones prácticas fundamentales ausentes en una teoría externa.

De todas formas, conviene advertir que nada de lo que dice Shapiro niega que las explicaciones externas también tengan relevancia práctica. El hecho de que no ofrezcan una metodología para determinar el contenido del derecho no dice nada respecto de otras informaciones igualmente valiosas que pueden aportar. Las explicaciones externas todavía se adecúan a los lineamientos de las ciencias naturales. En este sentido, las investigaciones enfatizan, entre otras cosas, la exigencia de comprobación empírica, la observación de regularidades, el establecimiento de relaciones causales entre los fenómenos abarcados por 
el objeto de estudio y la formulación de leyes generales, la capacidad predictiva y la cuantificación. Evidentemente, Shapiro no rechazaría el valor de los estudios institucionales comparativos, que intentan precisar los efectos de los esquemas alternativos sobre distintas variables. Por ejemplo, podemos comparar los sistemas de responsabilidad civil con los sistemas de compensación social para los accidentes de tránsito, y ver cuál de ellos produce una menor cantidad de daños, cuál de ellos produce una compensación mayor de las víctimas, cuáles son los efectos de cada uno de estos esquemas sobre los costes del transporte público y privado, etcétera. Toda esta información, que no puede ser extraída del mero análisis conceptual del discurso de los participantes, tendrá una gran relevancia práctica al momento de diseñar el plan óptimo para nuestra vida en comunidad. ¿Qué razón puede tener la comunidad para preferir un sistema de responsabilidad civil antes que un sistema de compensación social? Podría responderse que la responsabilidad civil implementa la justicia correctiva, por lo tanto, es moralmente obligatorio diseñar la compensación de daños de ese modo. Pero si descubriésemos que el sistema de responsabilidad civil deja a las víctimas sin compensación en la mayoría de los casos, ¿seguiríamos diciendo que es un imperativo moral contar con ese sistema?; y si luego descubriésemos que, como consecuencia de que los agentes dañadores quedan impunes, la cantidad de accidentes se multiplican y cada año mueren muchas más personas con este sistema que con un esquema general de seguro obligatorio, ¿seguiríamos insistiendo en que tenemos razones morales para implementar un derecho de daños tradicional? Creo que la relevancia práctica de las explicaciones externas está fuera de discusión, cualquiera sea la concepción de la moralidad que se sostenga, puesto que ofrecen información de cómo es el mundo.

En conclusión, la interpretación funcional de la concepción del derecho como plan social es defendible como modelo teórico, aunque no se adecue al proyecto que Shapiro tenía en mente. Esta explicación no puede responder a la pregunta de la identidad, o no puede responderla de modo que sirva para identificar lo que exige el derecho; pero de todas maneras, reformulando levemente las ideas de Shapiro, podría ofrecerse una respuesta como la siguiente: el derecho es un instrumento 
con el cual las comunidades pueden resolver sus problemas sociales, cualesquiera que sean, cuando ellos son tan complejos, numerosos y serios, y sus soluciones tan complejas, controvertidas o arbitrarias que otras formas de organización no jurídicas (la interacción espontánea, la improvisación o los acuerdos privados) se presentan como una manera menos eficiente para guiar, coordinar y controlar la conducta.

Por lo tanto, el enunciado funcional podría ser algo como lo siguiente: la función del derecho es permitir a los grupos sociales superar las circunstancias de la legalidad. Esto significa que: (1) el derecho usualmente permite a los grupos sociales superar las circunstancias de la legalidad ${ }^{65}$; y (2) si, caeteris paribus, las instituciones jurídicas estuvieran ausentes, entonces, la probabilidad de que los grupos sociales superasen las circunstancias de la legalidad serían inferiores.

Podría objetarse que esta explicación convierte al derecho en una clase funcional, pero no creo que sea necesario asumir ningún compromiso al respecto. Las teorías externas no están interesadas en "la naturaleza de las cosas"; tampoco se interesan por definiciones ${ }^{66}$. El programa teórico no incluye nada parecido a la captación de esencias; solo se interesa por determinar los beneficios producidos por aquellas instituciones que son habitualmente reconocidas como pertenecientes a cierta clase.

Shapiro no debería tener demasiadas objeciones en contra de esta formulación externa de su teoría. En efecto, sus intuiciones apuntan

${ }^{65}$ Cuando digo que el derecho usualmente permite a los grupos sociales superar las circunstancias de la legalidad dejo abierta la posibilidad de que exista derecho defectuoso. Así como puede existir un corazón defectuoso, cuya función es hacer circular la sangre aun cuando no pueda alcanzar ese resultado, también puede ocurrir que un sistema jurídico en concreto sea incapaz de organizar la conducta o de guiar el comportamiento. Esta podría ser una manera interesante de apoyar la tesis de que las regla validadas por una regla de reconocimiento incluyente son derecho aun cuando sean incapaces de hacer una diferencia práctica, es decir, de guiar la conducta. Conforme con esta explicación, las reglas de reconocimiento incluyentes serían un fundamento defectuoso de los sistemas jurídicos. No obstante, esta idea es incompatible con el positivismo excluyente que defiende Shapiro.

66 Por supuesto, existen diferentes opiniones al respecto. Véase Millikan, R. G., "In Defense of Proper Functions", Philosophy of Science, 56 (2) 1989, pp. 288-302, en pp. 295-297; Neander, K., "Functions as Selected Effects: The Conceptual Analyst's Defense", Philosophy of Science, 58 (2), 1989, pp. 168-184, en p.180. 
muchas veces en esa dirección. Esto puede observarse en su análisis de las reglas de propiedad, los contratos y la responsabilidad extracontractual. En su opinión, todas estas reglas "pueden comprenderse como planes generales cuya función es crear las condiciones favorables para que emerja un orden espontáneamente. En lugar de actuar como manos visibles que guían directamente las decisiones económicas, brindan a los agentes del mercado las habilidades para desarrollar sus propios planes maximizadores, de modo que la eficiencia económica general se maximice en el proceso"67. Claramente, esta interpretación de las instituciones principales del derecho privado sería rechazada por cualquier teórico que pretenda estudiarlas tomando en consideración el punto de vista interno ${ }^{68}$. Esto muestra que, pese a las intenciones de Shapiro, su teoría a veces ofrece explicaciones internas y otras puramente externas. Esto, argumentaré, no debe considerarse una incoherencia metodológica, sino una virtud.

En el próximo apartado intentaré mostrar por qué las explicaciones internas y las externas son complementarias. Abogaré, además, por una comprensión mixta de las prácticas jurídicas. Creo que cada perspectiva ilumina una parte de la realidad social. Ambas explicaciones tienen interés teórico y también relevancia práctica, aunque para cosas distintas. En esta línea, intentaré mostrar que la mejor interpretación de la teoría de Shapiro la concibe como una explicación mixta que profundiza el modelo iniciado por Hart.

\section{Hacia una comprensión mixta de las prácticas jurídicas}

El último argumento que deseo ofrecer está dirigido a mostrar que la mayoría de los teóricos del derecho anglosajones, desde la publicación de The Concept of Law, han quedado obnubilados por el punto de vista

${ }^{67}$ Shapiro, S., Legalidad, op. cit., p. 176.

68 Véase, entre muchos otros, Weinrib, E., "Understanding Tort Law", Valparaiso University Law Review, 23(3), 1989, pp. 485-526. 
interno ${ }^{69}$. Las críticas que Hart presentó contra Austin, que debían iluminar los problemas de las explicaciones basadas en un modelo puramente externo, han cegado a los teóricos a tal punto que solo se dedican a las interpretaciones internas, al análisis de los conceptos que se emplean en la práctica. Por ejemplo, buena parte de las críticas que reciben los partidarios del análisis económico del derecho tienen que ver con que la imagen que presentan de las instituciones jurídicas es irreconocible para sus participantes. Incluso sus defensores intentan mostrar que el análisis económico puede ofrecer una buena explicación interna ${ }^{70}$. En lugar de reivindicar el valor de las explicaciones externas, todos los teóricos procuran satisfacer el test de la inteligibilidad interna. Creo que es momento de recordar que el modo en que los participantes interpretan su propia realidad puede estar viciado por los mitos y las supersticiones con que el hombre común organiza su vida en sociedad. El estudio de estos aspectos es sin duda valioso, pero también lo es el de aquellas partes de la realidad que no están presentes en el esquema conceptual de los participantes.

Una potencial fuente de disconformidad podría venir del hecho de que aunque las explicaciones externas ofrezcan información valiosa se trataría de cuestiones contingentes que, por tanto, no pertenecen a la teoría general del derecho. Pero esto es un error. La teoría que estoy describiendo explicaría por qué cabe predecir que cualquier comunidad que adopte un determinado esquema de responsabilidad civil tendrá

${ }^{69}$ El positivismo jurídico europeo está un poco más dividido al respecto. Aunque la obra de Hart ha tenido un gran impacto, el realismo jurídico genovés se mantiene escéptico a veces sobre el proyecto metodológico general y otras veces sobre la precisión, corrección u originalidad de sus ideas. Véase Guastini, R., "Releyendo a Hart", Doxa. Cuadernos de filosofia del derecho, 37, 2014, pp. 99-110.

${ }^{70}$ Véase, entre otros, los intentos de Jody Kraus (Kraus, J. S., "Transparency and Determinacy in Common Law Adjudication: A Philosophical Defense of Explanatory Economic Analysis", Virginia Law Review, 93 (2), 2007, pp. 287-359). La excepción más clara es Richard Posner. En lugar de pensar el derecho privado y el derecho penal en términos de sus conceptos deberían ser concebidos como instrumentos. Una vez que se da ese paso, puede advertirse que las funciones del derecho privado y del derecho no son tan distintas: ambas ramas del derecho establecen un precio por ciertas conductas a fin de desalentarlas o, al menos, controlarlas. Véase Posner, R., Law and Legal Theory in England and America, Oxford, Clarendon Press, 1996, p. 54. 
menos accidentes que otra que prescinda de él. La teoría es general. Al igual que la noción de regla de reconocimiento sirve para analizar los distintos ordenamientos jurídicos concretos, los estudios funcionales o los modelos predictivos servirían para iluminar las realidades sociales concretas de cada grupo social.

Esta tesis no debería ser controvertida, puesto que incluso aquella parte de la realidad que depende exclusivamente de las creencias de la comunidad produce efectos en el mundo. Si las explicaciones internas mejoran nuestra percepción de los fenómenos sociales, seguramente mejoran solo una parte de ellos. Piénsese en el conocido ejemplo del dinero. Algo cuenta como dinero cuando los individuos de una comunidad lo tratan como instrumento de cambio y depósito de valor. Es decir, la existencia de dinero no es un hecho bruto, sino que requiere de la existencia de instituciones. Sin embargo, esto no niega que el dinero pueda cumplir funciones no intencionales, como preservar las relaciones de poder entre quienes tienen dinero y quienes no lo tienen ${ }^{71}$. Tampoco va en contra de la afirmación de que una teoría externa que ilumina los efectos positivos de contar con dinero como medio de cambio, en comparación con el trueque, nos ayuda a comprender con mayor profundidad nuestra realidad social.

En definitiva, para comprender completamente la realidad social no hay más alternativas que acudir a explicaciones mixtas. Creo que la teoría de Shapiro es un excelente ejemplo de esto. Por ello, al comienzo de este trabajo sostuve que existen razones para valorar su enfoque incluso si se rechaza la idea de que recurrir al concepto de plan social es necesario para suplir las supuestas falencias teóricas de Hart.

Shapiro, pese a todo, no es el primer autor que tiene estas intuiciones. Hart mismo, que en The Concept of Law propone un giro metodológico radical al enfatizar la importancia del punto de vista interno, ofrece una explicación mixta. Todo el mundo está familiarizado con ella, pero en la literatura no se ha advertido suficientemente que el

${ }^{71}$ Véase Searle, J., The Construction of Social Reality, New York, The Free Press, 1995, pp. 20-23 y 123. 
punto de vista interno cumple una función limitada en su teoría ${ }^{72}$. E1 punto de vista interno sirve para definir el concepto de regla social, que a su vez será imprescindible para explicar el fundamento de los sistemas jurídicos. Pero al explicar los elementos del derecho, es decir, la relación entre las reglas primarias y secundarias, Hart ofrece una típica explicación funcional externa. Su razonamiento puede ser reconstruido de la siguiente manera.

En primer lugar, Hart compara la manera en que una comunidad primitiva organizaría su conducta con la forma moderna de organización social. Las comunidades primitivas, obviamente, tienen reglas, en particular, reglas primarias o que imponen deberes. Estas reglas constituyen un conjunto de estándares separados, es decir, no conforman un sistema. Cualquier comunidad primitiva sufriría las debilidades de una estructura social integrada únicamente por normas primarias. Probablemente sufrirían un grado importante de incertidumbre respecto de qué reglas son parte de los estándares legítimos de la comunidad; un segundo problema estaría dado por las dificultades asociadas a la introducción y eliminación de reglas del conjunto existente. Un orden social conformado solo por reglas primarias es esencialmente estático. A fin de contar con un conjunto de reglas útiles para regular las circunstancias que atravesarán a lo largo de su historia en común, los grupos deben contar con una manera de modificar las reglas del sistema; por último, el tercer problema de un orden social constituido solo por reglas primarias es la ineficiencia del control social difuso. Probablemente surgirían gran cantidad de disputas relativas a si una regla ha sido infringida o la manera correcta de aplicar una regla. En breve, el primer paso en el argumento de Hart es identificar los defectos de los órdenes sociales primitivos.

El segundo paso es mostrar que estos tres defectos pueden ser solucionados con tres tipos de reglas. La regla de reconocimiento soluciona los problemas de incertidumbre, las reglas de cambio resuelven las defi-

72 Tiempo atrás, Shapiro sugirió que Hart estaba comprometido con una concepción funcional del derecho, aunque no desarrolló suficientemente la idea. En sus trabajos recientes, en cambio, parece haber abandonado esta línea argumental. Véase Shapiro, S., "On Hart's Way Out", op. cit.; Shapiro, S., "Law, Morality, and the Guidance of Conduct”, Legal Theory, 6 (2), 2000, pp. 127-170, p. 167. 
ciencias de los sistemas estáticos y las reglas de adjudicación establecen órganos con autoridad para decidir cuándo las reglas primarias han sido violadas. Cuando un sistema incluye este tipo de reglas, indiscutiblemente será un sistema jurídico ${ }^{73}$.

Nótese que, en esta explicación, la función de las reglas secundarias es opaca a los participantes, y que señalar sus efectos positivos para la comunidad resulta irrelevante para definirlas. En ninguna de las definiciones se incluye la función. Es decir, para comprender lo que es una regla de reconocimiento o una regla de cambio el intérprete de la realidad social no requiere indagar en sus funciones. Una regla de reconocimiento se define por ser aquella que especifica los criterios de validez de las normas del sistema, no aquella que elimina la incertidumbre respecto de qué reglas forman parte de él. Podría uno pensar que la función se infiere de la definición, en el sentido de que se sigue necesariamente de que $\mathrm{R}$ sea una regla de reconocimiento que $\mathrm{R}$ tiene la disposición a reducir la incertidumbre respecto de qué reglas forman parte del sistema. Pero esto obvia que la explicación funcional es algo más que la identificación de algo que el ítem tiene la disposición a hacer. También se sigue necesariamente de que $\mathrm{M}$ sea una mancha en un leopardo que $\mathrm{M}$ tiene la disposición a camuflarlo en ciertos entornos, pero no puede inferirse que ello sea necesariamente beneficioso para el leopardo sin considerar las circunstancias en que se encuentra. Por esta razón, entre otras, no diríamos que la explicación que apunta a los efectos beneficiosos de $\mathrm{M}$ para los leopardos es parte de una explicación de la naturaleza de los leopardos. Del mismo modo, los ritos religiosos tienen la capacidad de cohesionar a los feligreses, pero no diríamos que los beneficios de esa cohesión se siguen necesariamente de que algo sea un rito religioso.

La explicación de Hart sobre las funciones de las reglas de reconocimiento, cambio y adjudicación ofrece una información adicional a la que puede obtenerse mediante el análisis conceptual. No se limita al punto de vista interno, aunque de todas maneras ilumina una parte importante del fenómeno jurídico. Hart podría haber prescindido de

${ }^{73}$ Hart, H. L. A., The Concept of Law, op. cit., pp. 91-97 (113-121). 
esta explicación externa. Hubiese bastado con señalar que el derecho, a diferencia de otras prácticas normativas, es la unión de reglas primarias y secundarias. Es decir, hubiese sido suficiente con señalar que el derecho es una práctica institucionalizada. Entonces, si avanza en las funciones externas de las reglas secundarias es porque este aspecto de su explicación pone de relieve algo importante, algo que su explicación conceptual deja de lado: los efectos beneficiosos de contar con cierto tipo de reglas.

Por esta razón creo que la crítica de Stephen Perry, según la cual Hart realiza un juicio evaluativo de la práctica que estudia al sostener que un sistema normativo que solo incluya reglas primarias es defectuoso $^{74}$, es equivocada. Hart está ofreciendo una explicación funcional, y la identificación de ciertas necesidades o defectos a ser solucionados es un paso necesario para la adscripción de función. Perry podría responder que, precisamente por esta razón, las explicaciones funcionales siempre requieren presupuestos valorativos. No obstante, esta valoración creo que es epistémica. A diferencia de las explicaciones en ciencias naturales, en las que resulta difícil decir que los leopardos, por ejemplo, tienen un punto de vista sobre lo que es valioso para ellos ${ }^{75}$, en las ciencias sociales aquello que es valioso para los seres humanos puede ser identificado con relativa facilidad por el teórico. No solo contamos con métodos para medir las preferencias de las comunidades, sino que además formamos parte de alguna comunidad. Si, como es razonable también asumir, todos los colectivos tienen necesidades organizativas similares, por el hecho de ser miembros de un grupo social podremos saber cuáles son. Es cierto que puede discutirse que toda comunidad valore la certeza, la posibilidad de modificar su sistema normativo con relativa celeridad y

74 Perry, S., "Hart's Methodological Positivism", Legal Theory, 4, 1998, pp. 427- 467, en p. 438.

75 En estos casos, al explicar que las manchas del leopardo tienen por función camuflarlos para hacerlos cazadores más eficaces, el teórico proyecta su propio esquema conceptual en la explicación. Probablemente, los leopardos no tengan una concepción del camuflaje, pero tampoco parece descabellado adscribir esta función si se presupone que: 1) prolongar su vida es beneficioso para los leopardos; 2) los leopardos necesitan cazar para prolongar su vida; y 3) el camuflaje los hace cazadores más eficientes. Dadas estas premisas, es razonable concluir que las manchas producen el efecto positivo de camuflarlos y que esto es beneficioso para el leopardo. 
la capacidad de decidir cuándo las normas son violadas; pero si resulta plausible sostener que estos constituyen beneficios, es razonable adscribir a las reglas secundarias las funciones que Hart señala. Quien pretenda negar que estos sean beneficios, deberá también negar que la guía eficiente de la conducta de los miembros de la comunidad es algo valioso. Pero si alguien negase esto último, dudaríamos de su capacidad para comprender la vida en sociedad.

Evidentemente, también para Shapiro la parte externa de la teoría de Hart debe resultar extremadamente interesante, ya que en su libro, cuando en el capítulo IV se ocupa de Hart, su análisis comienza con los problemas del mundo prejurídico. Esto sugiere que existe un vínculo intelectual entre estos dos autores que va mucho más allá de lo obvio. La concepción del derecho como plan no solo intenta profundizar y mejorar la teoría interna de Hart sino que, tal vez sin proponérselo, avanza sobre la teoría externa. Además de los problemas del mundo prejurídico, Shapiro ofrece una explicación de las ventajas de los sistemas jurídicos respecto de otras formas de organización social mucho más sofisticada que la de Hart. Solo por esto los teóricos del derecho deberían recibir esta obra con algún entusiasmo.

\section{Bibliografía}

Boorse, C., "Wright on Functions", The Philosophical Review, 85 (1), 1976, pp. 70-86.

Brown, R., Explanation in Social Science, Chicago, Aldine Publishing Company, 1963.

Cummins, R., "Functional Analysis", The Journal of Philosophy, LXXII (20), 1975, pp. 741-765.

Durkheim, E., Las reglas del método sociológico, México, Fondo de Cultura Económica, [1895], 1986.

Dworkin, R., Law's Empire, Cambridge-Mass., Harvard University Press, 1986. 
Diego M. Papayannis

Elster, J., Ulysses and the Sirens. Studies in rationality and irrationality, revised edition, Cambridge, Cambridge University Press, 1984,

Griffiths, P. E., "Functional Analysis and Proper Functions", British Journal for the Philosophy of Science, 44, 1993, pp. 409-422.

Guastini, R., "Releyendo a Hart", Doxa. Cuadernos de filosofía del derecho, 37, 2014, pp. 99-110.

Hart, H. L. A. (1961), The Concept of Law, Second Edition, Oxford, Oxford University Press, 1994.

Hart, H. L. A., El concepto de derecho, Buenos Aires, Abeledo-Perrot, 1963, traducción de Genaro Carrió.

Hart, H. L. A., "Commands and Authoritative Reasons", en Essays on Bentham, Oxford, Clarendon Press, 1982.

Hart, H. L. A., "Legal Duty and Obligation", en Essays on Bentham, Oxford, Clarendon Press, 1982.

Hart, H. L. A., Post scriptum al concepto de derecho, México, UNAM, 2000, traducción de Rolando Tamayo y Salmorán.

Himma, K. E., "Inclusive Legal Positivism", en Coleman, J. L., Shapiro, S., Himma, K. E., Oxford Handbook of Jurisprudence and Philosophy, Oxford, Oxford University Press, 2002.

Kraus, J. S., "Transparency and Determinacy in Common Law Adjudication: A Philosophical Defense of Explanatory Economic Analysis", Virginia Law Review, 93 (2), 2007, pp. 287-359.

Lewis, D., Convention. A Philosophical Study, Cambridge, Mass., Harvard University Press, 1969.

Macdonald, G. y Pettit, P., Semantics and Social Science, London-BostonHenley, Routledge and Kegal Paul, 1981.

Martin, M., Verstehen: The Uses of Understanding in the Social Sciences, New Jersey, Transaction Publishers, 2000.

McLaughlin, P., What Functions Explain. Functional Explanation and SelfReproducing Systems, Cambridge, Cambridge University Press, 2001.

Millikan, R. G., Language, Thought, and Other Biological Categories. New foundations for Realism, Cambridge-Mass. - London, England, The MIT Press, 1984.

Millikan, R. G., "In Defense of Proper Functions", Philosophy of Science, 56 (2) 1989, pp. 288-302. 
Neander, K., "Functions as Selected Effects: The Conceptual Analyst's Defense", Philosophy of Science, 58 (2), 1989, pp. 168-184.

Perry, S., "Hart's Methodological Positivism", Legal Theory, 4, 1998, pp. 427- 467.

Posner, R., Law and Legal Theory in England and America, Oxford, Clarendon Press, 1996.

Raz, J., The Authority of Law, Oxford, Oxford University Press, 1979.

Raz, J., Practical reasons and norms, Oxford, Oxford University Press, 1990.

Raz, J., Ethics in the Public Domain, Oxford, Oxford University Press, 1996.

Searle, J., The Construction of Social Reality, New York, The Free Press, 1995.

Shapiro, S., "On Hart's Way Out”, Legal Theory, 4 (4), 1998, pp. 469507.

Shapiro, S., "Law, Morality, and the Guidance of Conduct", Legal Theory, 6 (2), 2000, pp. 127-170.

Shapiro, S., "What is the internal point of view", Fordham Law Review, 75 (3), 2006, pp. 1157-1170.

Shapiro, S., Legalidad, Madrid-Barcelona, Marcial Pons, 2014, traducción de Papayannis, D. M. y Ramírez Ludeña, L.

Schwartz, J., "Functional Explanation and Metaphysical Individualism", Philosophy of Science, 60 (2), 1993, pp. 278-301.

Von Wright, G. H., Explanation and Understanding, London, Routledge \& Kegan Paul, 1971.

Warnock, G. J., The Object of Morality, London, Methuen, 1971.

Weber, M., Wirtschaft und Gesellschaft, Tubinga, J. C. B. Mohr, 1922. Citado por la traducción española de Giner, S., La acción social: Ensayos metodológicos, Barcelona, Ediciones Península, 1984.

Weinrib, E., "Understanding Tort Law", Valparaiso University Law Review, 23(3), 1989, pp. 485-526.

Winch, P., The idea of a Social Science and its Relation to Philosophy, Londres, Routledge \& Kegan Paul, 1958.

Wright, L., "Functions", The Philosophical Review, 82 (2), 1973, p. 139168. 